\title{
Hipergêneros e multiletramento no ensino de língua materna: uma experiência no uso das TICs em sala de aula
}

\author{
Ernani Cesar de Freitas* \\ Mateus Fonseca Pereira"
}

\section{Resumo}

Este trabalho tematiza a utilização das tecnologias da informação e comunicação (TICs) no contexto escolar do ensino médio. O objetivo é aplicar atividades diversificadas em sala de sala de aula, para o estudo da língua materna, com base em hipergêneros, visando promover o multiletramento dos alunos. O estudo justifica-se porque é perceptível o ritmo acelerado que as TICs são disseminadas, o que tem gerado novas formas e ferramentas de interação e, consequentemente, novos gêneros discursivos e/ou hibridização dos já existentes. A base teórica do estudo fundamenta-se principalmente nos postulados de Maingueneau (2005, 2010) sobre hipergêneros e de Rojo (2009, 2012, 2013) sobre multiletramentos e leitura na hipermídia com base em Santaella (2004, 2007, 2013). Trata-se de uma pesquisa exploratória e bibliográfica, desenvolvida mediante pesquisa-ação levada a efeito em uma escola pública de ensino médio. Como resultado, destaca-se que a adoção de hipergêneros e a utilização das TICs no estudo da língua materna podem auxiliar no processo de ensino, em especial no letramento/multiletramento de alunos do ensino médio.

Palavras-chave: Hipergêneros. Multiletramento. TICs.

\section{Introdução}

Esta pesquisa buscou agregar teorias diversificadas, como algumas oriundas da análise de discurso francesa e outras relacionadas a princípios comunicacio-

* Doutor em Letras (PUCRS). Pós-doutorado em Linguística Aplicada e Estudos da Linguagem (PUCSP/LAEL). professor permanente do PPGL da Universidade de Passo Fundo. E-mail: ecesar@upf.br

** Bacharel em Design Gráfico pela UFPel. Bacharel em Teologia pelo Fatev. Mestre em Letras pela Universidade de Passo Fundo. E-mail: mateusfp@hotmail.com

Data de submissão: set. 2015 - Data de aceite: nov. 2015 http://dx.doi.org/10.5335/rdes.v11i2.5372 
nais e educacionais surgidos em países anglófonos. Tem como tema a utilização das tecnologias de informação e comunicação (TICs) no contexto escolar do ensino médio (EM), e mais especificamente no primeiro ano desse ciclo. A justificativa dessa escolha parte do interesse na utilização de equipamentos eletrônicos no contexto escolar de adolescentes. $\mathrm{O}$ trabalho legitima-se porque é claramente perceptível o ritmo acelerado no qual as TICs são aperfeiçoadas, o que tem gerado novas formas e ferramentas de interação e, consequentemente, novos gêneros discursivos, além da sua hibridização. Ademais, vivemos também em um contexto multicultural constantemente exposto a textos híbridos, compostos por múltiplas linguagens e que permitem semioses plurivariadas.

Assim, delimitamos a seguinte questão norteadora: o desenvolvimento de práticas leitoras e de produção de textos com base em hipergêneros, no estudo da língua materna, pode contribuir para o multiletramento de alunos no EM. Daí decorre o objetivo deste estudo: desenvolver, aplicar e avaliar práticas leitoras e de produção de textos em sala de aula, com base em hipergêneros, no estudo da língua materna, visando promover o multiletramento de alunos do EM.

O marco teórico deste estudo é constituído por conceitos relacionados à leitura e ao letramento (SOARES, 2002; CORACINI, 2005; SANTAELLA, 2013), a jovens leitores, por meio de gêneros discursivos, com foco principal nas con- cepções: de Maingueneau (2005, 2010), a respeito de hipergêneros; nas de alguns integrantes do New London Group Grupo Nova Londres (2000), de Lemke (2010) e de Rojo (2009, 2012, 2013) em relação a multiletramentos.

Quanto à metodologia utilizada neste trabalho, desenvolvemos uma pesquisa exploratória e bibliográfica estabelecida mediante pesquisa-ação com abordagem qualitativa, com a finalidade de produzir conhecimentos práticos relacionados ao ensino da língua materna no sentido de proporcionar possíveis contribuições ao fazer docente, em relação à perspectiva do multiletramento dos alunos. O corpus principal utilizado durante a pesquisa (corpus principal) foi o website $\mathrm{O}$ Hobbit - Viagem pela Terra Média, criado para auxiliar na promoção da franquia de filmes homônima baseada no livro de J. R. R. Tolkien.

Este estudo está organizado de forma a apresentar as questões teóricas em um primeiro momento e, após, será apresentada a metodologia de pesquisa e o desenvolvimento da análise. Nas três primeiras partes da fundamentação teórica, apresentamos e comentamos conceitos sobre as práticas de leitura e letramento aplicadas a adolescentes com a utilização das TICs.

Nas três seções de discussão teórica seguintes, utilizamos uma terminologia mais específica, para desenvolver a conceituação que fundamenta e referencia a interface entre os temas que se inter-relacionam, tais como a concepção de 
gênero em Bakhtin (1997, 2010), que é discutida e destacada por Maingueneau (2013) e Marcuschi (2002, 2008), com comentários desse último autor a respeito da ênfase dada pelos Parâmetros Curriculares Nacionais (PCNs) ao estudo dos gêneros no ensino de língua em ambiente escolar. Após, relacionamos os gêneros com os hipergêneros, termo que necessita de mais estudos e pesquisas em nosso país, pois, conforme percebemos, requer a adoção do conceito de multiletramento ao se pensar sobre práticas aplicadas em sala de aula que estejam engajadas no sentido de preparar os alunos para suas trajetórias socioprofissionais.

A sétima parte expõe os detalhes da pesquisa quanto à questão metodológica, pormenorizando a prática da investigação: nesse momento, justificamos a utilização da pesquisa-ação e definimos suas fases; procedemos à apresentação que caracteriza os sujeitos e estabelece os corpora utilizados, com destaque ao dispositivo de análise. Na sequência, com a exibição dos dados coletados durante a execução, realizamos a análise propriamente dita.

\section{Leitura, letramento e os jovens (não)leitores do século XXI}

Esta seção é dedicada a algumas questões referentes a realidades de leitura surgidas com o advento de novas tecnologias interacionais eletrônicas, que impactam de maneira muito visível a experiência dos sujeitos que são alvo desta pesquisa: adolescentes, alunos do primeiro ano do EM. Para isso, abordamos alguns conceitos relacionados ao texto no ambiente digital e analisamos como os jovens têm lidado com a leitura.

Iniciamos a discussão destacando que muito tem sido ponderado sobre o papel da escola na formação de novos leitores. Zilberman (2009) delineia um interessante histórico de como a escola foi incumbida de desenvolver as práticas de escrita e leitura nos cidadãos de nações modernas, partindo do princípio de que todos os cidadãos têm o direito à alfabetização em prol do progresso da nação. Contudo, sabemos da constante crise que o Brasil experiencia, considerando tanto a relação com seu pequeno público leitor quanto ao número efetivo de leitores letrados. A essa situação aflitiva, Zilberman (2009) atribui a profunda crise na escola e no sistema educacional brasileiro como um todo, sendo tal fato evidenciado em publicações que, através dos anos, têm estudado o problema tentando compreendê-lo apontando possíveis soluções.

Todavia, ao mesmo tempo em que o Brasil apresenta vários números desencorajadores referentes à responsabilidade das escolas de nível fundamental e médio (o país tem, segundo relatório da Unesco (2009), cerca de 13 milhões de analfabetos, considerando-se pessoas acima de 15 anos de idade), alguns resultados positivos têm sido alcançados (de acordo com o Índice de Desenvolvimento da Educação Básica (INEP, 2011)) e nos dão uma perspectiva de que há, sim, uma 
solução. São numerosas, inclusive, as publicações que tratam das práticas leitoras no Brasil, tanto devido às diferentes concepções de leitura quanto por conta das distintas possibilidades de leitura que se apresentam. Podemos pensar em um ideal de leitura, que ocorre de forma silenciosa por meio do livro de papel, ou podemos ampliar nossa compreensão e considerar as novas alternativas que se apresentam mediante diversos suportes e mídias que reconfiguram a consciência humana, como na proposta de Santaella (2007), que acarreta novas práticas e novas possibilidades. Essa nova realidade está diretamente relacionada à problemática vigente, visto que, diante dessa condição, o texto também é influenciado, pois herda características maleáveis, sem limites preestabelecidos.

Dessa maneira, com a finalidade de abordar algumas das formas como a leitura se apresenta na contemporaneidade, refletimos no espaço seguinte sobre o impacto que as tecnologias digitais têm causado no modo como interagimos com o texto e suas consequentes produções de sentido.

\section{Possibilidades leitoras} com o uso das novas tecnologias de informação e comunicação (TICs)

Ao relacionar o ato de ler com os diferentes suportes nos quais ele pode acontecer, em diferentes mídias, e sabendo que a leitura apresenta-se em diferentes gêneros, sua própria concepção no século XXI precisa ser atualizada. Coracini faz alguns apontamentos pertinentes quando afirma que "ler pode ser definido pelo olhar" (2005, p. 19). Dessa forma, o leitor/ observador busca o sentido no texto ou na obra em apreciação (descoberta do sentido). Além disso, é possível uma interação na qual se estabelece o processo cognitivo que coloca o leitor ante o autor; o bom leitor conseguiria estabelecer diferentes sentidos a partir de seus processos cognitivos e conhecimentos prévios já adquiridos (construção do sentido).

Atualmente, temos, inclusive, acesso à produção de textos restritos ao mundo digital, com características próprias muito diferentes daquelas encontradas nas páginas palpáveis, sobretudo no que diz respeito à utilização de tipografia em movimento, aliada ao uso de sons e imagens. E sobre a leitura em dispositivos digitais, o filósofo francês Pierre Lévy (1996) afirma que o leitor em tela é mais "ativo" que o leitor em papel, tendo em vista que ler em tela é enviar um comando a um computador para que projete uma realização parcial do texto em uma superfície luminosa. Dessa forma, Lévy (1996) considera a tela informática uma nova "máquina de ler", o lugar onde uma reserva de informação possível vem se realizar por seleção, aqui e agora, para um leitor particular. Esse novo universo de criação e leitura de signos, que ocorre quando o leitor interage com as mídias digitais, difere-se muito daquele que ocorre por meio dos textos e vídeos produzidos em computadores, 
porém acessados em mídias tradicionais, já que esses não apresentam propriedades estéticas diferentes das produções feitas completamente em equipamentos analógicos.

Ao falar sobre leitura em tela chegamos ao hipertexto, texto de suporte informático que alcança virtualmente todos os pontos da rede ao qual está conectada a memória onde se inscreve seu código, sendo seu endereço transitório e de pouca importância, pois ocupa computadores do tipo servidores; seu endereço pode mudar tão rapidamente como se faz uma nova busca na internet. $\mathrm{O}$ hipertexto tem sua atualização durante a própria navegação, ou seja, sua atualização acontece em situações de utilização. Além disso, o hipertexto digital permite associar na mesma mídia sons, imagens (estáticas ou animadas) e textos. Assim, "o hipertexto digital seria, portanto, definido como uma coleção de informações multimodais dispostas em rede para navegação rápida e 'intuitiva". (LÉVY, 1996, p. 44). Se o hipertexto é um espaço de percursos de leituras possíveis, o leitor/navegador participa pelo menos da edição do texto que lê, pois é ele que determina sua organização final. Aquele que participa da estruturação do hipertexto, do traçado pontilhado das possíveis dobras do sentido já é um leitor.

Interpretando e ampliando alguns conceitos e concepções de Lévy, Santaella também trata da leitura na hipermídia como um processo de escritura por parte do leitor, "pois, na hipermídia, a leitura é tudo e a mensagem só vai se escrevendo na medida em que os nexos (nós) são acionados." (2004, p. 175). Santaella chama de leitor imersivo aquele que se apresenta frente ao texto eletrônico que emerge nesse ambiente. De acordo com a autora, o leitor de telas é mais "ativo" devido à liberdade que tem ao considerar as diversas conexões, em "um contexto dinâmico de leitura comutável entre vários níveis midiáticos" (2004, p. 175), o que cria um novo modo de ler, visto que no contexto comunicacional da hipermídia o infonauta lê, escuta e olha ao mesmo tempo. Esse leitor imersivo, então, tem pela frente adaptar-se aos avanços tecnológicos que transformam os computadores em máquinas cada vez menores e mais velozes. Com isso, podemos dizer que a navegação, essa atividade performativa e cognitiva que se tornou a nova forma de ler, não está presa a um único tipo de equipamento.

Devido às espantosas mudanças ocorridas no meio da cultura digital, Santaella (2013) anuncia o surgimento de um novo tipo de leitor: o leitor ubíquo. Um dos fatos mais importantes para o surgimento desse leitor, no que diz respeito aos avanços tecnológicos, são os equipamentos de telefonia celular de alta performance, os chamados smartphones, e a sua capacidade de estar sempre on-line por meio das redes de internet móvel. Santaella explica o surgimento do leitor ubíquo: 
À mobilidade física do cidadão cosmopolita foi acrescida a mobilidade virtual das redes. Ambas as mobilidades entrelaçaram-se, interconectaram-se e tornaram-se mais agudas pelas ações de uma sobre a outra. A popularização gigantesca das redes sociais do ciberespaço não seria possível sem as facilidades que os equipamentos móveis trouxeram para se ter acesso a elas, a qualquer tempo e lugar. É justamente nesses espaços da hipermobilidade que emergiu o leitor ubíquo, trazendo com ele um perfil cognitivo inédito que nasce do cruzamento e mistura das características do leitor movente com o leitor imersivo (2013, p. 21).

A partir dessa compreensão da ubiquidade, Santaella caracteriza esse novo tipo de leitor como alguém que apresenta "uma prontidão cognitiva ímpar para orientar-se entre nós e nexos multimídia, sem perder o controle da sua presença e do seu entorno no espaço físico em que está situado." Como consequência, o foco de atenção desse leitor é "continuamente parcial", pois ele responde a diversos estímulos "sem se demorar reflexivamente em nenhum deles." São

[...] leitores para os quais não há tempo nem espaço para a reflexão, este tipo de habilidade mental que precisa da solidão paciente para se tecer e que, por isso mesmo, é característica primordial do leitor contemplativo (2013, p. 22).

Todas essas transições e transformações levantam questionamentos sobre a real capacidade de esse leitor ubíquo conseguir lidar com tudo aquilo que lêestando efetivamente alfabetizado para isso. Como aponta Almeida (2005), seria de se esperar que não existissem mais analfabetos funcionais entre pessoas inseridas no mercado de trabalho. Toda- via, números do Instituto Brasileiro de Geografia e Estatística de 2012 ainda indicam que, considerando a população acima de 15 anos de idade, 18,3\% (quase 30 milhões de pessoas) são analfabetos funcionais.

Almeida (2005) ainda menciona que estudos referentes ao analfabetismo funcional levaram à definição do conceito de letramento. Essa pesquisadora adota a definição de letramento cunhada por Soares, e que pode ser elucidada como "a apropriação da leitura e da escrita para exercer a cidadania, ter condições de acesso à cultura da sociedade letrada e corresponder às suas demandas utilizando o ler e o escrever em práticas sociais" (2001, p. 20). Para essa autora, a apropriação da escrita é diferente da alfabetização, visto que esta se refere à capacidade de codificar e decodificar a escrita, enquanto letramento diz respeito a apreender essa tecnologia de escrita e utilizá-la socialmente.

Segundo Soares, é necessário um ajuste na definição de letramento no momento atual devido à introdução de novas modalidades de práticas sociais de leitura e escrita propiciadas pelas recentes tecnologias de comunicação eletrônica. A autora também comenta que "a tela, como novo espaço de escrita, traz significativas mudanças nas formas de interação entre escritor e leitor, entre escritor e texto, entre leitor e texto e até mesmo, mais amplamente, entre o ser humano e o conhecimento" (2002, p. 151); por essa razão, tais mudanças acarretam consequências sociais, cogni- 
tivas e discursivas, o que configuraria um letramento digital.

É esse letramento baseado na cultura do hipertexto, o letramento digital, que Almeida (2005) considera essencial para que o cidadão possa exercer sua cidadania plenamente na atualidade. É realmente muito fácil pensar em exemplos práticos nos quais o letramento digital é essencial em nosso país, considerando que há serviços e responsabilidades com os quais lidamos na vida cotidiana que necessariamente empregam as tecnologias digitais. É o caso dos caixas eletrônicos dos bancos, da declaração do imposto de renda ou mesmo do procedimento de votação nas eleições.

Assim, reconhecendo que são os jovens aqueles que têm maior contato com o texto digital e com os equipamentos nos quais é difundido, apresentamos na próxima seção algumas das características marcantes dessa nova geração de leitores/alunos.

Diante dessa situação, considerando tais sujeitos como alunos, o desafio é ensinar-lhes de forma criativa, que desperte a atenção e os mantenham engajados. Essas questões são tratadas na seção seguinte.

\section{Desafios relacionados à leitura diante das novas TICs}

Em razão da complexidade do assunto, não há perspectiva de responder a todas as perguntas levantadas na seção anterior, apenas é possível ter certo lampejo sobre aquilo que o jovem leitor lê cotidianamente. Como se trata de uma idealização desse sujeito, é necessário considerar seriamente se é ideal o fato de que esse jovem leia textos de periódicos, e-mails, mensagens de celular, etc.; a leitura de livros não figura no topo das listas apresentadas (INSTITUTO PRÓ-LIVRO, 2011).

De fato, a leitura no meio digital está acontecendo e ela nos permite situações bastante variadas, por exemplo, a leitura de textos em movimento, textos com tipografias e cores diferentes, textos que apresentam uma música de fundo, etc., tudo isso disponibilizado em hipertexto. Este, que é a grande fonte de novas experiências de leitura em suportes digitais, permite a hibridação de linguagens que são fruídas mediante uma navegação não linear por meio de links (SANTAELLA, 2007), podendo ser realizada em um computador ou outro equipamento digital.

Com o barateamento dos dispositivos eletrônicos a partir do início do século XXI, praticamente qualquer usuário tem a possibilidade de produzir e editar, em sua máquina, textos e imagens, sons e vídeos, o que faz dos computadores muito mais do que aparatos de armazenamento de informações, considerando-os equipamentos que digitalizam e disponibilizam cada uma das linguagens. Seguindo a mesma funcionalidade, temos atualmente também os equipamentos chamados smartphones e tablets, que podem ser considerados os novos microcomputadores, pois geralmente preservam as 
mesmas funções e características de um notebook, por exemplo - têm processadores, disco rígido, memória, sistema operacional, etc.; apenas o tamanho os diferencia. Além disso, outra característica marcante de todos esses equipamentos é sua possibilidade de estar conectado a todo o momento à internet, condição indispensável para a maioria dos usuários.

Esse fruir simultâneo de diferentes linguagens, esse navegar em hipertextos que nos levam a outros hipertextos sem requerer nenhuma ordem preestabelecida, causam grande impacto na experiência leitora de cada sujeito. Essa leitura torna-se uma navegação, o que altera o perfil cognitivo daqueles que Santaella (2004, 2013) chama de leitores imersivos e ubíquos, pois eles têm a possibilidade de estabelecer sua coparticipação na produção das mensagens conforme escolhem determinado percurso no mundo virtual.

Assim, o ponto-chave na formação de leitores criteriosos, que estejam aptos a lidar com os mais diversos suportes, reside naqueles que promovem a leitura. Não afirmamos com isso que esses promotores devem simplesmente adotar tudo aquilo que surge de novidade no contexto da educação por meio de mídias digitais, mas negá-las só os afastará cada vez mais de seu objetivo, qual seja, nas palavras de Rojo: formar pessoas que "saibam guiar suas próprias aprendizagens na direção do possível, do necessário, e do desejável, que tenham autonomia e saibam buscar como e o que aprender, que tenham flexibilidade e consigam colaborar com a urbanidade" (2012, p. 27). Devemos compreender que uma das principais tarefas de nossos tempos é formar leitores competentes para que possam interagir com qualquer gênero discursivo, seja uma mensagem de celular, seja um artigo científico, sabendo que a cada estágio de seu desenvolvimento o jovem precisa dar passos que o leva à maturidade como leitor, o que implicará, consequentemente, a maturidade em outras áreas de sua vida socioprofissional.

Na próxima seção, apresentamos a conceituação mais específica de alguns termos utilizados na análise deste estudo, partindo da questão dos gêneros, passando por hipergêneros até chegarmos à proposta de multiletramentos.

\section{Gêneros discursivos, hipergêneros e multiletramento}

Este espaço é dedicado às questões relativas aos gêneros do discurso e ao impacto que as tecnologias digitais causam sobre eles a ponto de originar outros gêneros. Tais ponderações são pertinentes considerando o enfoque que educadores e pesquisadores da área das letras têm dado aos gêneros durante o processo de formação de leitores, o que é corroborado pelo texto orientador sobre o ensino de Língua Portuguesa encontrado nos Parâmetros Curriculares Nacionais, que será comentado adiante nesta seção. Dessa forma, para iniciar a reflexão sobre os gêneros, partimos de concepções mais clássicas 
sobre o assunto, principalmente com base em Mikhail Bakhtin, em seus textos que compõem Estética da criação verbal (1997).

Uma das características que faz com que a obra de Bakhtin tenha se destacado é, provavelmente, como mencionam Arcoverde e Arcoverde (2007), o fato de o teórico russo ter sido aquele que abrangeu o uso do termo para a área de estudos da linguagem, o que tem servido de base para muitos outros estudiosos, sendo constantemente citado por diversos analistas de discurso. De início, quando começamos a pesquisar sobre o assunto, percebemos que no estudo dos gêneros tanto a terminologia gêneros do discurso ou discursivos quanto gêneros textuais é adotada. Aqui, o propósito não é debater sobre a expressão mais pertinente, visto que a maioria dos estudiosos define os termos da mesma forma; as variações acontecem em razão de concepções não hegemônicas, mas também não divergentes oriundas de correntes teóricas diversas.

Segundo Bakhtin (2010), o ponto de partida no processo comunicacional, o signo, está ligado ao contexto social no qual está inserido. O autor faz essa afirmação para elaborar o pensamento de que todo signo é ideológico, o que gera no indivíduo um processo mental de organização de ideias, também ideológico. Descartando esse marco teórico sobre formação de ideias, o que interessa é o fato de a língua ser um fenômeno social (BAKHTIN, 2010) e sua utilização estar relacionada com "todas as esferas da atividade humana" e "efetuar-se na forma de enunciados" (1997, p. 279).
Os gêneros do discurso resultam em formas-padrão de enunciados, determinadas e inseridas em um contexto socio-histórico, sendo a manifestação clara de práticas sociais. Em outras palavras, para Bakhtin (1997), somente nos comunicamos falando ou escrevendo, por exemplo, por meio de gêneros do discurso, uma vez que os sujeitos têm um infindável repertório de gêneros à disposição para o seu jogo comunicacional, mesmo que, muitas vezes, nem se deem conta disso. Isso porque tais gêneros nos são dados, conforme Bakhtin, "quase da mesma forma com que nos é dada a língua materna, a qual dominamos livremente até começarmos o estudo da gramática" (1997, p. 282).

Maingueneau relaciona os gêneros a categorias do discurso, afirmando que tais categorias alteram-se em razão de suas aplicações corriqueiras. Elas "correspondem às necessidades práticas da vida cotidiana" (2013, p. 65). Dessa forma, na mesma direção de Bakhtin, Maingueneau destaca que os gêneros do discurso são "dispositivos de comunicação que só podem aparecer quando certas condições socio-históricas estão presentes" (2013, p. 67).

Esse linguista, longe de apenas ficar em especulações conceituais, ainda salienta duas utilidades prática dos gêneros: a economia cognitiva que garante ao locutor; asseguram a comunicação. Ao falar sobre economia cognitiva, o linguista francês utiliza o pensamento de Bakhtin: 
Aprendemos a moldar nossa fala pelas formas do gênero e, ao ouvir a fala do outro, sabemos logo, desde as primeiras palavras, descobrir seu gênero, adivinhar seu volume e a estrutura composicional usada, prever o final, em outras palavras, desde o início somos sensíveis ao todo do discursivo [...] Se os gêneros do discurso não existissem e se não tivéssemos o domínio deles e fôssemos obrigados a construir cada um de nossos enunciados, a troca verbal seria impossível (1997, p. 285).

Contudo, como o próprio Bakhtin alerta, "alguns gêneros transmutam de outros gêneros" (1997, p. 281), ou seja, por mais estáveis que as características de um gênero sejam, tais aspectos existem em função das atividades sociais às quais os gêneros servem. Assim, é natural compreender que, conforme os atores sociais criam e estabelecem novas práticas comunicativas, novos gêneros do discurso são concebidos.

A partir dessa compreensão bakhtiniana de metamorfose e formação de novos gêneros, Marcuschi destaca que, com as novas tecnologias digitais, surgem novos gêneros textuais, que não são absolutamente novos, pois não existem "sem uma ancoragem em outros gêneros já existentes" (2002, p. 20). Podemos, portanto, pensar em alguns exemplos dessas transmutações: o telefonema tem a conversa face a face na sua origem; 0 e-mail tem a carta; o blog tem o diário pessoal, etc. Mas não é somente pelo fato de a concepção de gênero ser pertinente para destacar que os gêneros da cultura impressa têm se transformado em novos gêneros relacionados às tecnologias digitais, que o estudo dos gêneros é importante. Além disso, nos últimos anos, a questão do estudo dos gêneros tem sido grandemente enfatizada no ensino de línguas no ambiente escolar em nosso país.

Isso se confirma quando analisamos os PCNs (BRASIL, 1997, 1998, 2000, 2002), que destacam o conceito dos gêneros para o estudo da língua portuguesa/ linguagens desde o ensino fundamental, principalmente no que se refere às práticas de leitura e escrita envolvidas no processo de letramento. Nessa direção, lemos nos PCNs:

Formar escritores competentes, supõe, portanto, uma prática continuada de produção de textos na sala de aula, situações de produção de uma grande variedade de textos de fato e uma aproximação das condições de produção às circunstâncias nas quais se produzem esses textos. Diferentes objetivos exigem diferentes gêneros e estes, por sua vez, têm suas formas características que precisam ser aprendidas (BRASIL, 1997, p. 44).

Os PCNs ainda salientam a maleabilidade atual dos gêneros, considerando diferentes situações de uso de quem produz e para quem se produz determinado texto.

Os gêneros discursivos cada vez mais flexíveis no mundo moderno nos dizem sobre a natureza social da língua. Por exemplo, o texto literário se desdobra em inúmeras formas; o texto jornalístico e a propaganda manifestam variedades, inclusive visuais; os textos orais coloquiais e formais se aproximam da escrita; as variantes linguísticas são marcadas pelo gênero, pela profissão, camada social, idade, região (BRASIL, 2000, p. 21).

Um dos objetivos finais do estudo de diferentes gêneros é expresso assim: 
Como os textos ganham materialidade por meio dos gêneros, parece útil propor que os alunos do ensino médio dominem certos procedimentos relativos às características de gêneros específicos (BRASIL, 2002, p. 78).

Dessa forma, a concretização das práticas pedagógicas propostas pelos PCNs seria, consoante Marcuschi, redutora e homogeneizadora, visto que elas privilegiam conteúdos muito específicos. Esse pesquisador propõe que parâmetros curriculares como os PCNs enfoquem "no nível conceitual, explanatório" (2008, p. 211). É nesse sentido que se configura o presente trabalho, pois compreendemos que o objetivo dos educadores não é apresentar aos alunos todos os gêneros existentes, o que seria impossível, mas sim tornar os alunos aptos a desenvolver uma competência em gêneros variados, de maneira que, mais facilmente, tenham habilidades suficientes quando em contato com gêneros que desconheciam até o momento.

$\mathrm{Na}$ sequência, as argumentações teóricas são alicerçadas mediante o conceito de hipergênero proposto por Maingueneau (2005, 2010), ao tratar da materialização do discurso por meio das TICs, sobretudo na internet.

\section{Hipergênero: um conceito multiforme}

No que se refere à materialização dos gêneros do discurso na internet, Maingueneau (2010) apresenta um entendimento diferenciado daquilo que tem sido postulado por muitos teóricos de gêneros quando analisam o meio virtual.
Isso acontece a partir da introdução do conceito de hipergênero nas teorias do linguista francês.

De início, o termo hipergênero não tem relação direta, nem surge do termo hipertexto, forma conectada não linear como se apresentam as páginas de internet. Outrossim, integrando tal conceito na teoria dos gêneros do discurso, Maingueneau afirma que

[...] os hipergêneros não sofrem restrições socio-históricas: eles apenas enquadram uma larga faixa de textos e podem ser usados durante longos períodos e em muitos países. As restrições que eles impõem são muito pobres (2010, p. 131).

Dessa forma, um blog, por exemplo, deve ser considerado um hipergênero, justamente por existirem blogs dos tipos mais diversos os quais estabelecem diferentes gêneros do discurso (diário pessoal, diário de viagens, notícias, resenhas de filmes e livros, etc.). Percebemos que Maingueneau (2010) amplia a concepção de Bakhtin (1997) sobre os gêneros, cujo conceito o filósofo russo destaca ser baseado num mundo onde o impresso prevalecia, no qual entrava em jogo a hierarquia dos suportes e dos componentes da cena de enunciação.

Com o intuito de compreender essa conceituação na integra, é importante observarmos que Maingueneau começa suas postulações sobre hipergênero antes mesmo de considerar os meios de comunicação digitais, falando mais especificamente sobre o diálogo, o diálogo filosófico e as cartas. Inicia sua explanação com o comentário: 
Um hipergênero, antes de tudo, "formata" um texto: não é um gênero de discurso, um dispositivo de comunicação socio-historicamente definido, mas um modo de organização textual que encontramos em tempos e em lugares muito variados e no interior dos quais se pode desenvolver uma encenação do discurso muito variada (2005, p. 135).

Com efeito, ao classificarmos um texto como diálogo, carta ou diário, temos certa formatação, porém sem saber nada muito específico sobre seu funcionamento. Assim, no interior de um hipergênero, "podem-se desenvolver variadas encenações da palavra" (2010, p. 133).

Voltando a tratar sobre a comunicação por meio da internet, Maingueneau (2010) afirma que nela também a cenografia tem papel central. Para compreendermos o destaque dado pelo autor francês à cenografia ao falar de hipergêneros, é importante realizar uma retrospectiva teórica acerca desses conceitos em seus diversos escritos. Por exemplo, ao discutir o discurso literário, Maingueneau enfatiza a diferença entre "situação de comunicação" e "situação de enunciação" (cena de enunciação), pois para ele na primeira considera-se o processo de comunicação do ponto de vista sociológico, do exterior, enquanto na segunda situação considera-se o processo do interior, "mediante a situação que a fala pretende definir, o quadro que ela mostra no próprio movimento em que se desenrola" (2012, p. 250). O linguista francês explica que "um texto é na verdade o rastro de um discurso em que a fala é encenada." Em outras palavras, Maingueneau salienta que:
[...] o discurso pressupõe essa cena de enunciação para poder ser enunciado, e, por seu turno, ele deve validá-la por sua própria enunciação: qualquer discurso, por seu próprio desdobramento, pretende instituir a situação de enunciação que o torna pertinente (2008b, p. 75).

Por esse aspecto legitimador do discurso e por ser legitimada por ele, Maingueneau (2008a, 2008b, 2013) destaca que a cenografia passa por um "enlaçamento paradoxal", pois ela é,

[...] ao mesmo tempo, origem e produto do discurso; ela legitima um enunciado que, retroativamente, deve legitimá-la e fazer com que essa cenografia da qual se origina a palavra seja precisamente a cenografia requerida por tal discurso (POSSENTI, 2008, p. 206, grifo do autor).

Relacionando os conceitos de cenografia e hipergênero, ao considerar a comunicação por meio da internet, Maingueneau afirma que a grande questão é que a rede de computadores altera tanto as condições de comunicação quanto aquilo que se concebe por gênero e também a própria noção de textualidade. Isso porque, no mundo virtual, há duas situações que devem ser salientadas:

a) "na internet as coerções genéricas estão se tornando mais fracas", como resultado do fato que no ambiente virtual "todas as unidades comunicacionais são da mesma ordem (elas são "websites")" (2010, p. 132-133). Quando esse teórico faz a afirmação de que todas as unidades são websites, o que ele quer referir é que, em realidade, elas estão baseadas na natureza do hipertexto, "submetidas a uma 
larga escala de restrições técnicas" (2010, p. 133) que "implica uma nova maneira de ler e a possibilidade de passar instantaneamente de uma "página" para outra em um espaço aberto" (2010, p. 137);

b) a cenografia tem o papel principal, pois a questão é "encenar a comunicação de acordo com as estratégias de seus produtores" (2010, p. 133).

Nesse sentido, Maingueneau enfatiza que essas alterações no jogo comunicacional implicam uma nova forma de textualidade, pois na internet não temos apenas "textos", ou como o autor menciona (2010, p. 136), "esses sites não são mais 'fala', eles são páginas em uma tela de computador, imagens", que integram fotos e textos. Por esses motivos, na textualidade de navegação na internet, o que prevalece é o par hipergênero/cenografia.

Considerando todas essas questões concernentes ao mundo virtual e ainda visando ao trabalho prático em sala de aula, em relação ao foco nos gêneros do discurso e enfatizados pelos PCNs, apresentamos, na seção seguinte, o conceito de multiletramento e sua relevância para o contexto escolar.

\section{Uma nova concepção: de letramento para multiletramentos}

Ao abordarmos termos como gêneros discursivos e hipergêneros e considerá-los na perspectiva do ensino, é necessá- rio resgatarmos o conceito de letramento tratado no início deste trabalho. Sumariamente, o letramento está relacionado à utilização social das tecnologias de escrita e leitura. No entanto, quando essas práticas sociais de leitura e escrita ocorrem em diversos contextos culturais e também estão relacionadas à utilização de equipamentos digitais, não podemos falar de somente um tipo de letramento, mas sim de letramentos múltiplos, ou multiletramentos.

A noção de multiletramento foi criada originalmente por um grupo de pesquisadores em 1996, que se reuniu para discutir novas maneiras de ensinar na sociedade contemporânea, em constante transformação. $\mathrm{O}$ grupo se autodenominou Grupo Nova Londres (New London Group), pois reuniu-se na cidade de Nova Londres, localizada no estado de Connecticut, nos Estados Unidos. Algumas das preocupações principais do grupo foi $o$ impacto da multiplicidade de canais de comunicação e a crescente e evidente heterogeneidade linguística e cultural relacionada à sala de aula.

A escolha do termo multiletramento ocorreu para que houvesse um foco na crescente diversidade local e conectividade global, pois o fato de lidar com essas transformações linguísticas culturais tornou-se algo central no cotidiano das pessoas em suas vidas profissionais, cívicas e privadas. Nas palavras dos pesquisadores do New London Group, o termo multiletramentos pode ser definido da seguinte forma: 
Uma palavra que escolhemos porque descreve dois importantes argumentos que devemos ter com a emergente ordem cultural, institucional e global. O primeiro argumento se engaja com a multiplicidade de canais e mídias de comunicação; o segundo com a crescente saliência de diversidade linguística e cultural (2000, p. 5).

A pedagogia dos multiletramentos foca-se em modos de representação que vão muito além da língua apenas. Esse aumento no contato entre pessoas de culturas diferentes significa uma não padronização da linguagem, ao contrário do que era proposto no início da escolarização, quando o intuito era eliminar as diferenças e estabelecer o poder do povo dominante por meio da linguagem. Por essa razão, o multiletramento precisa ser capaz de habilitar os alunos a negociar significados por meio de linguagens permeadas por variações de todos os tipos, sejam elas causadas por diferenças sociais, culturais, tecnológicas, etc. O objetivo disso é propor um novo senso de vida cívica em que as diferenças são utilizadas como um recurso produtivo (NEW LONDON GROUP, 2000).

O uso dessas mídias digitais na atualidade, por intermédio de computadores, tablets e smartphones, por exemplo, requer usuários que saibam lidar com uma gama diversa de habilidades semióticas e de leitura e escrita, que requerem também o uso da intuição para poder dar conta de sistemas autoexplicativos. Nesse sentido, aqueles usuários que apresentam maiores facilidades poderiam inclusive ser comparados praticamente como técnicos de informática por outros usuários mais inexperientes.
De acordo com Lemke, as pessoas precisam tornar-se capazes de lidar com as tecnologias digitais bem como com as novas possibilidades na vida cotidiana daqueles que as dominarem:

Sem todas estas habilidades, os futuros cidadãos estarão tão desempoderados quanto aqueles que hoje não escrevem, leem ou usam a biblioteca. Estas são as habilidades necessárias para nossos letramentos futuros, aquelas de que todos nós precisaremos. Porém, as novas tecnologias da informação também abrem novas possibilidades para ampliar nossos letramentos em novas formas e muitos de nós escolheremos desenvolver tipos adicionais de letramentos de que talvez nem todos precisem, mas que trarão grandes benefícios para aqueles que os adquirirem (2010, p. 464).

Assim, conforme Lemke (2010), todos esses diversos letramentos têm o objetivo de satisfazer às variadas demandas da vida social; por essa razão, eles se proliferam de diversas formas: visual, midiático, cultural, computacional, matemático, emocional, etc. A linguagem é dinâmica e constantemente reconstruída pelos usuários em resposta aos ambientes sociais onde vivem.

Lemke também faz uma interessante observação sobre a relação entre os gêneros discursivos e o letramento:

Um letramento é sempre um letramento em algum gênero e deve ser definido com respeito aos sistemas sígnicos empregados, às tecnologias materiais usadas e aos contextos sociais de produção, circulação e uso de um gênero particular. Podemos ser letrados em um gênero de relato de pesquisa científica ou em um gênero de apresentação de negócios. Em cada caso as habilidades de letramento específicas e as comunidades de comunicação relevantes são muito diferentes (2010, p. 457). 
Se desejarmos formar alunos multiletrados, é necessário proporcionar-lhes o contato com uma vasta diversidade de gêneros - no meio impresso ou digital. É essa preocupação que expressa Dias (2012) ao mencionar que, no contexto escolar, o letramento que proporciona aos alunos a promoção do sentido por meio de gêneros digitais é muitas vezes relegado em segundo plano. Todavia é de responsabilidade do professor ampliar seu círculo de atuação, não focando somente em práticas de letramento canonizadas, mas também incluindo processos interativos que aumentam as produções de sentido por parte dos alunos. Além disso, Dias menciona Rojo, que destaca que o multiletramento não deve "ignorar ou apagar os letramentos das culturas locais e deve colocar os alunos em contato com os letramentos valorizados, universais e institucionais" (Rojo, 2009, p. 107 apud Dias, 2012, p. 103). Com efeito, Rojo destaca que

[...] um dos objetivos principais da escola é justamente possibilitar que seus alunos possam participar das várias práticas sociais que se utilizam da leitura e da escrita (letramentos) na vida da cidade, de maneira ética, crítica e democrática" (2009, p. 107, grifo do autor).

A questão da multiplicidade cultural dentro dos multiletramentos é fortemente desenvolvida por Rojo (2009, 2012, 2013), pois, para essa autora, diferentes culturas locais vivem as práticas de letramento de maneira diferente. Dessa forma, não há possibilidade de considerar pares antagônicos como culto/inculto, cultura erudita/popular, central/marginal, canônico/de massa. Por essa razão, Rojo (2013) destaca a importância do pluralismo cívico desenvolvido na escola, visando à formação de cidadãos multiculturais, aptos a viver suas identidades multifacetadas e a conviver na diversidade. Nessa perspectiva, Rojo se expressa por intermédio das palavras de Kalantzis e Cope:

[...] a escola deve buscar desenvolver nos alunos a habilidade de expressar e representar identidades multifacetadas apropriadas a diferentes modos de vida, espaços cívico e contextos de trabalho em que cidadãos se encontram; a ampliação dos repertórios culturais apropriados ao conjunto de contextos em que a diferença tem de ser negociada. A capacidade de se engajarem numa política colaborativa que combina diferenças em relações de complementaridade (2000, p. 135 apud Rojo, 2013, p. 15, tradução do autor).

De acordo com os enfoques teóricos observados sobre os multiletramentos, compreendemos que seu objetivo primordial é formar cidadãos multicapacitados e autônomos, flexíveis para constantes mudanças. Vislumbrando essa finalidade, é possível simplificar as características essenciais dos multiletramentos nas palavras que Rojo sintetiza do New London Group (2000), de Kalantzis e Cope (2000) e de Lemke (2010):

- são interativos; mais que isso, colaborativos;

- eles fraturam e transgridem as relações de poder estabelecidas, em especial as relações de propriedade (das máquinas, das ferramentas, das ideias, dos textos [verbais ou não]); 
- eles são híbridos, fronteiriços, mestiços (de linguagens, modos, mídias, culturas) (2012, p. 23).

\section{Trabalhando com hipergêneros na sala de aula}

Neste espaço, apresentamos uma breve descrição do corpus principal, os procedimentos metodológicos, as fases da pesquisa e o contexto no qual ela foi realizada. Tal percurso foi planejado de forma a contemplar a questão norteadora estabelecida no início deste trabalho, que nos conduziu a propor atividades em sala de aula, utilizando textos encontrados no corpus principal, os quais visam à promoção do multiletramento dos alunos.

Segundo as definições de Prodanov e Freitas (2013), esta pesquisa caracteriza-se como qualitativa e de natureza aplicada, visando à produção de conhecimentos práticos relacionados aos possíveis problemas associados à abordagem de hipergêneros na sala de aula. Em relação ao objetivo do estudo, trata-se de uma pesquisa exploratório-explicativa, pois busca destacar o atual estado da arte dos principais fundamentos que embasam este estudo, além de interpretar os fenômenos estudados, com a preocupação de identificar seus fatores determinantes. Quanto aos procedimentos técnicos adotados, foi realizada uma pesquisa-ação, que previu em sua fase preliminar a realização de uma pesquisa bibliográfica com o objetivo de levantar o referencial teórico relacionado aos conceitos e situações práticas a serem analisadas.

No contexto específico deste estudo, avaliando principalmente as variantes tempo, corpora, sujeitos e possíveis implementações, adaptamos o ciclo da pesquisa-ação para três etapas distintas: etapa 1 - coleta de dados, etapa 2 análise, planejamento e implementação, etapa 3 - análise de resultados. Essas três etapas são detalhadas na sequência:

A etapa 1 foi composta por:

a) Pesquisa preliminar: pesquisa bibliográfica, fundamentação teórica, delimitação do tema, entrevistas e observações de aula, análise de material didático e aplicação de questionário;

b) Definição do problema: descrição e explicação dos fatos na forma da questão norteadora apresentada na introdução deste trabalho;

c) Delimitaçãor do objetivo deste estudo: conforme consta na introdução.

A etapa 2 foi constituída de:

a) Elaboração do plano de ação: elaboração das atividades e respectivos guias do professor (planos de aula) a serem aplicadas no contexto de sala de aula visando alcançar os objetivos traçados;

b) Implementação e coleta de dados: aplicação prática das atividades em sala de aula, registradas em relatório. 
A etapa 3 compreendeu:

a) Avaliação: a partir dos relatórios da aplicação das atividades e questionário posterior;

b) Disseminação: acontece, principalmente, por meio da publicação deste trabalho, além de outros documentos produzidos paralelamente, como os resultados do questionário posterior e o relatório final da prática, entregue à coordenação pedagógica e direção da escola onde a pesquisa foi realizada.

O denominado corpus principal da pesquisa, o website O Hobbit - Viagem pela Terra Média, é um conjunto de páginas disponibilizado on-line em novembro de 2013, como parte da campanha de divulgação da franquia de filmes $\mathrm{O}$ Hobbit, dirigido, produzido e adaptado por Peter Jackson do livro homônimo de J. R. R. Tolkien e distribuído pela Warner Bros. Pictures. Essa franquia foi concebida sob a forma de três filmes, com datas de lançamento programadas para dezembro de 2012 (Uma jornada inesperada), dezembro de 2013 (A desolação de Smaug) e dezembro de 2014 (A batalha dos cinco exércitos). Como visava promover uma ação específica de comunicação e marketing, talvez seja mais apropriado compreender Viagem pela Terra Média como um hotsite, ou seja, um tipo de página de internet que possui vida útil determinada, de maior apelo visual e com foco em um público específico.
Quanto ao contexto, encontramos uma escola de ensino médio que autorizou a realização da pesquisa e que se mostrou disposta a colaborar com este estudo. Por uma questão logística elegemos uma escola pública da cidade de Passo Fundo, RS. Além disso, tal escola tem sua qualidade de ensino em alto estigma na sociedade local, o que poderia fazer-nos facilmente pensar que é uma escola sem problemas, ou com problemas mínimos. Contudo, a partir da notoriedade do estabelecimento, vale observar que o "problema" para a pesquisa-ação pode ser qualquer atividade "voltada para intervir na realidade social" (PRODANOV; FREITAS, 2013, p. 50). Nesse caso, especificamente, tratamos de possíveis melhorias e inovações práticas no ensino de língua portuguesa com o uso das TICs.

Para conseguir chegar aos alunos/ sujeitos que fizeram parte da pesquisa, entramos em contato com uma das coordenadoras pedagógicas da escola que, tão logo sabendo do interesse dos pesquisadores, contatou as professoras de português, que concluíram ser o primeiro ano do ensino médio o grupo ideal. Em segundo momento, contatamos a professora responsável pelas turmas de primeiro ano, e escolheu uma turma específica para participar da pesquisa, pois considerava esse grupo mais receptivo e aberto visto a natureza do estudo proposto. Dessa forma, os sujeitos/atores diretos da pesquisa foram os professores pesquisadores, a professora titular e os 
29 alunos da turma de primeiro ano do ensino médio, que tinham entre quatorze e dezesseis anos de idade - onze meninos e dezoito meninas.

Os principais pressupostos teóricos mobilizados na construção da análise foram os postulados de Maingueneau (2005, 2010) sobre hipergêneros, utilizados como referência para a elaboração das atividades aplicadas em sala de aula. Posteriormente, foi solicitado que os alunos e a professora titular respondessem um questionário sobre tal prática, além da produção de relatório sobre as aulas ministradas, que foram analisados segundo referência de Rojo (2012) para verificar se os multiletramentos foram alcançados.

\section{Análise: uma experiência de ensino com (multi) letramento(s)}

Um dos objetivos deste trabalho foi produzir atividades de sala de aula que promovessem o multiletramento dos alunos por meio de um hipergênero (o website O Hobbit - Viagem pela Terra Média), que serviu como ponto de partida para que aos alunos exercitassem alguns gêneros discursivos em práticas leitoras e de produção de textos. Com essa finalidade, o processo de criação das atividades foi balizado nos seguintes critérios práticos: a viabilidade de aplicação em sala de aula, o número de alunos, o número de aulas ministradas, a duração de cada período, o conteúdo programático regular abordado na disciplina de língua portuguesa, assuntos de conhecimento geral discutidos no momento (eleições, racismo, homofobia). A maneira como as atividades foram elaboradas visava a agilizar sua realização em sala de aula, considerando a interação proposta entre os alunos e também o processo de produção textual, que requeria mais tempo dos alunos.

Durante a criação das atividades foram selecionadas imagens, tipografias e elementos ornamentais que remetessem ao universo ficcional do livro e dos filmes O Hobbit. Para o tamanho das páginas, foi escolhido um formato que não fugisse daquilo que é manuseado cotidianamente pela maioria da população e que facilitasse a impressão com baixo custo (folhas A4, orientação paisagem). Nas Figuras 1 e 2, é possível visualizar parte das atividades criadas. 
Figura 1 - Sequência didática 1, página 1

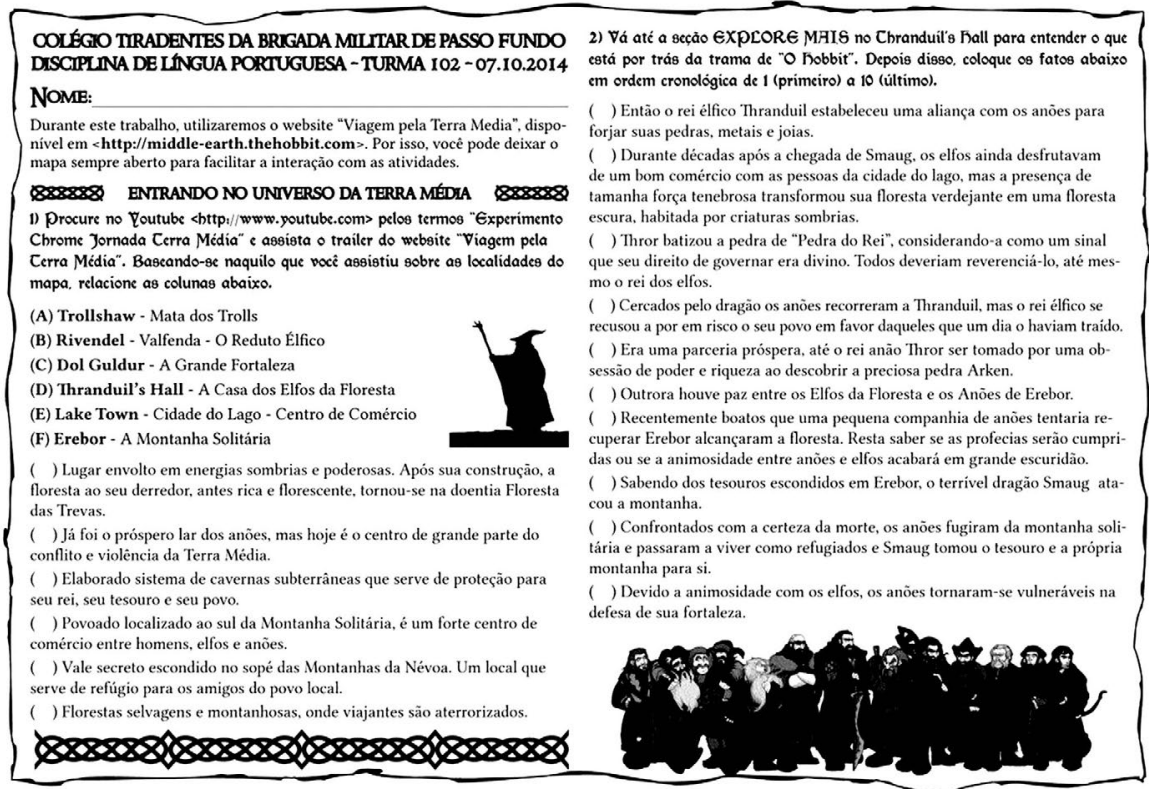

Fonte: elaborado pelos pesquisadores.

Figura 2 - Sequência didática 1, página 2

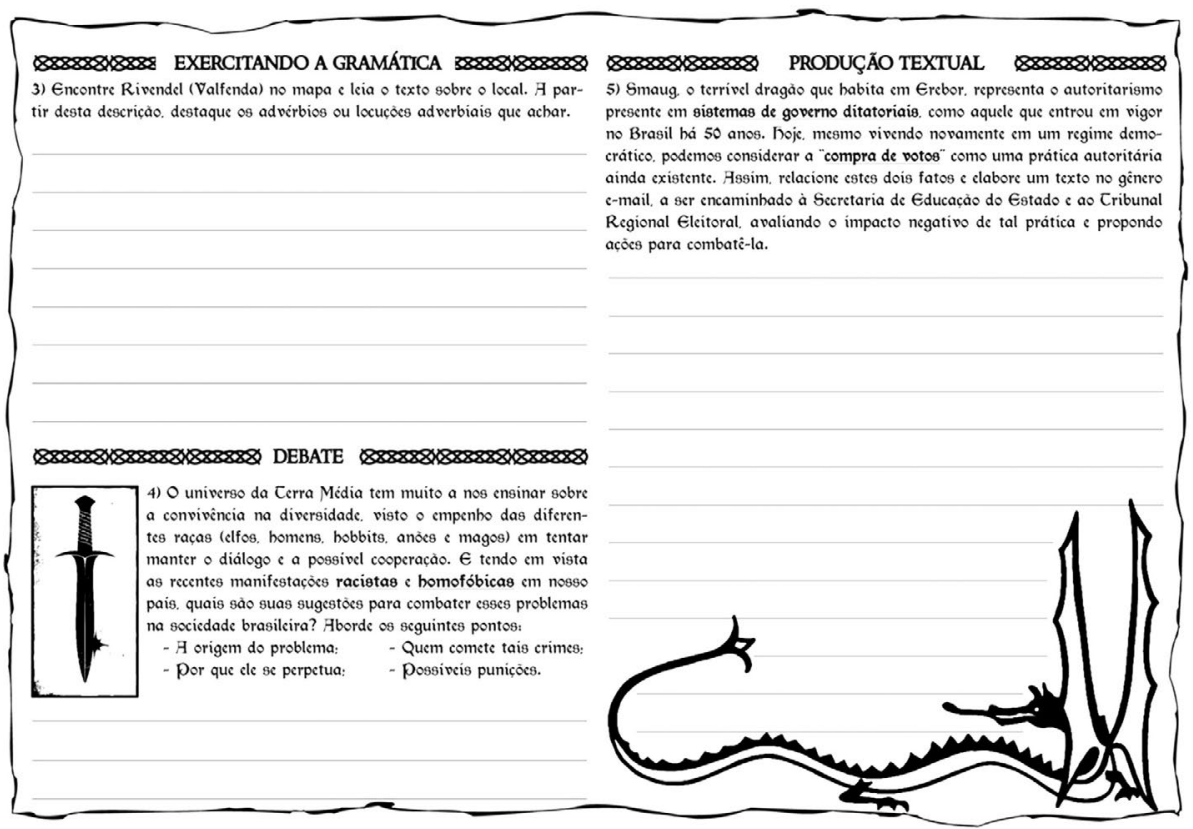

Fonte: elaborado pelos pesquisadores. 
Retomando o objetivo deste estudo, a ideia foi compreender como hipergêneros podem ser utilizados para a formulação de atividades que promovam o multiletramento de alunos do ensino médio. Conforme abordado anteriormente, o hipergênero utilizado como corpus principal apresentava as características de textualidade da internet (MAINGUENE$\mathrm{AU}, 2010$ ). Maingueneau retoma a ideia de que há "três formas básicas de mídia (oral, impressa e eletrônica)" (2010, p. 136), cada uma com diferentes formas de textualidade. Assim, o esquema de análise baseado na cena de enunciação, afirma Maingueneau (2010), está, de fato, relacionado à textualidade controlada (linear, tabular) da mídia impressa. Por esse motivo, na textualidade de "navegação de internet", a concepção de gênero deve ser substituída por hipergênero, visto que a cenografia se sobressai (escolha de cores, imagens, fontes, layout, etc.), de acordo com o quadro de comunicação imposto, segundo a intencionalidade de seu produtor. É assim que essa cenografia cria o enlaçamento paradoxal proposto por Maingueneau (2008a, 2008b), ao envolver o leitor/coenunciador/usuário por meio de textos e imagens estáticas, imagens em movimento, vídeos e jogos eletrônicos, sendo a cenografia ideal para tal texto. Isso evidencia as características essenciais de um hipergênero na concepção de Maingueneau (2005, 2010), o qual apresenta limites genéricos muito fracos e coloca a cenografia em destaque.
Dessa forma, a tarefa final do trabalho consistiu em, a partir das atividades de sala de aula propostas, analisar se o conceito de multiletramento, adotado neste estudo, foi alcançado ou não durante a pesquisa. Para isso, foi necessário estabelecer um dispositivo aferidor que possibilitasse essa compreensão. Com esse intuito, utilizamos o referencial proposto por Rojo (2012) com base no New London Group (2000), em Kalantzis e Cope (2000) e em Lemke (2010). Para chegarmos ao(s) multiletramento(s), deveríamos passar por alguns pressupostos, detalhados no Quadro 1: multiplicidade de linguagens, uma nova ética, novas estéticas, multiplicidade de culturas e culturas múltiplas e letramentos críticos. Quadro 1 - Pressupostos para o(s) multiletra-
mento(s)

\begin{tabular}{|l|l|}
\hline $\begin{array}{l}\text { Multiplicidade } \\
\text { de linguagens }\end{array}$ & $\begin{array}{l}\text { Utilização de textos que apresen- } \\
\text { tassem múltiplas semioses - nas } \\
\text { mídias impressas, nas mídias au- } \\
\text { diovisuais ou eletrônicas. }\end{array}$ \\
\hline Nova ética & $\begin{array}{l}\text { Não baseada na propriedade (di- } \\
\text { reitos de autor), mas sim no diá- } \\
\text { logo entre novos interpretantes } \\
\text { e que se alicerçassem nos letra- } \\
\text { mentos críticos. }\end{array}$ \\
\hline Novas estéticas & $\begin{array}{l}\text { Respeito a diferentes "gostos", } \\
\text { diferentes valorações estéticas. }\end{array}$ \\
\hline $\begin{array}{l}\text { Multiplicidade } \\
\text { de culturas }\end{array}$ & $\begin{array}{l}\text { Valoração de letramentos locais } \\
\text { e marginalizados, além daqueles } \\
\text { privilegiados pela escola ou con- } \\
\text { siderados de "alta" cultura, por } \\
\text { uma sociedade constituída de } \\
\text { seres heterogêneos. }\end{array}$ \\
\hline $\begin{array}{l}\text { Letramentos } \\
\text { críticos }\end{array}$ & $\begin{array}{l}\text { Textos que promovessem a for- } \\
\text { mação de analistas críticos. }\end{array}$ \\
\hline
\end{tabular}

Fonte: elaborado pelos pesquisadores com base em Rojo (2012), New London Group (2000), Kalantzis e Cope (2000) e Lemke (2010). 
Nenhum desses pressupostos foi colocado em posição de destaque em relação aos outros, nem mesmo há uma lógica sequencial entre um e outro. Todos apareceram, segundo Rojo (2012), no mesmo patamar. Por essa razão, ao criar, elaborar e planejar as atividades de sala de aula com base no corpus principal, elas foram balizadas pelos pressupostos do Quadro 1, visando qualificar e promover o multiletramento dos alunos, o que seria confirmado ou não ao final da pesquisa realizada.

Para verificar se o objetivo proposto neste trabalho foi alcançado, tivemos que contar com o auxílio de relatórios de prática de sala de aula e de relatórios de questionários respondidos pelos alunos e pela professora titular, considerando o cruzamento das informações com aqueles parâmetros adotados durante a elaboração das atividades (ROJO, 2012).

O planejamento das atividades procurou contemplar o uso de diversos gêneros discursivos acessados por meio do hipergênero que constituiu o corpus principal e outros encontrados no meio impresso, apresentando assim a multiplicidade de linguagens requerida para o multiletramento. Nesse sentido, tal diversidade de modos semióticos pôde ser percebida em atividades nas quais os alunos tiveram contato com música, vídeo, charadas e literatura para trabalhar a questão da influência da tradição oral na cultura popular. Nessas mesmas atividades, os alunos também tiveram a criatividade estimulada por meio de uma produção textual guiada de um texto com características da oralidade.

Ao comentar que os multiletramentos passam por uma nova ética baseada no diálogo, Rojo (2012) faz referência ao caráter colaborativo das mais diversas produções contemporâneas, sejam elas textuais, musicais, vídeos, etc., influenciadas por aquilo que as tecnologias digitais permitem (copiar, colar, compartilhar, etc.); há casos nos quais não existe apenas um autor em destaque. Isso foi exercitado durante todas as produções em sala de aula, nas quais os alunos foram estimulados a trabalhar em conjunto, principalmente na construção do pensamento coletivo após o debate que contemplou os temas racismo e homofobia.

Esse debate também foi muito relevante para proporcionar a expressão da multiplicidade de culturas presente na sala de aula, mais um dos aspectos que os multiletramentos devem observar (ROJO, 2012). Nessa atividade, os alunos expuseram suas diferentes culturas, expressas na forma de suas opiniões ao grande grupo, muitas vezes baseadas em pré-conceitos, regionalismos, diferentes histórias familiares e influenciadas pela religiosidade. Mesmo correndo o risco de causar animosidades em sala de aula, por se tratar de tópicos relativamente polêmicos, houve muito respeito entre todos os participantes, que tiveram a oportunidade de influenciar e serem influenciados por outro.

A oportunidade de expressar novas estéticas, por meio de juízo de valor e 
"gosto" pessoal, foi possível por meio de uma resenha proposta. Isso porque, por mais que seja cheio de imagens e apresente jogos eletrônicos, o corpus principal não foi e nem é necessariamente um website que agrade a todos. Isso diz respeito ao letramento crítico, pois também foi requerido que os alunos avaliassem sua eficiência no que concerne à navegação realizada nele, visto que apresenta uma nova tecnologia diante da qual, invariavelmente, em algum momento, o usuário/ leitor ainda não se apresentará como um leitor imersivo (SANTAELLA, 2004). Essa atividade também apresentou uma proposta diferente quanto à produção desse gênero discursivo, pois geralmente é produzido em sala de aula, e mesmo por jornalistas profissionais, resenhas de livros, filmes, álbuns de música, e não de websites. Além disso, o letramento crítico foi trabalhado nos diversos momentos em que os alunos precisaram expressar sua opinião, como na produção textual sobre política.

A proposta de estimular o multiletramento foi bem-sucedida. Em primeiro momento, isso se deve por respeitar os parâmetros estabelecidos por Rojo (2012), com base no New London Group (2000), em Kalantzis e Cope (2000) e Lemke (2010). Além disso, também consideramos a importância dada por Lemke (2010, p. 457) para a relação entre os diferentes gêneros e os letramentos múltiplos, pois, para esse autor, "teremos tantos letramentos quanto o número de gêneros multimidiáticos".
Concluímos, portanto, que o hipergênero escolhido como corpus principal da pesquisa, o website Viagem pela Terra Média, foi muito versátil como motivador das atividades de sala de aula propostas visando ao multiletramento dos alunos. Em primeiro lugar, isso se deve ao fato de enquadrarem largas faixas de textos e permitirem diversas encenações da palavra (MAINGUENEAU, 2010), o que facilitou a elaboração de atividades que abordassem diferentes gêneros discursivos. Em segundo lugar, considerando que na sociedade atual a ideia de letramento não está vinculada somente a textos estáticos, compostos por palavras ou frases, mas, sim, a textos vinculados a imagens, sons e vídeos, o que é próprio da textualidade eletrônica (MAINGUENEAU, 2010), um hipergênero no meio digital coloca em funcionamento diversas habilidades e aptidões dos leitores/ usuários, os quais apenas terão êxito em sua navegação se forem devidamente multiletrados.

\section{Considerações finais}

Este estudo teve como tema a utilização das TICs no contexto escolar do primeiro ano do EM, em um colégio estadual na cidade de Passo Fundo, RS, mais especificamente a utilização de enfoques teórico-aplicados que abordam conceitos de hipergêneros para multiletramento no ensino da língua materna.

Neste trabalho, tomamos por base a seguinte questão norteadora: o de- 
senvolvimento de práticas leitoras e de produção de textos com base em hipergêneros, no estudo da língua materna, pode contribuir para o multiletramento de alunos no EM. Esse questionamento surgiu por conta do nosso interesse em pesquisar sobre possibilidades de uso das TICs em processos de ensino e aprendizagem da língua portuguesa. A partir disso, floresceram outros conceitos-chave abordados, para fundamentação teórica da pesquisa desenvolvida, que foram necessários e apropriados para a compreensão das práticas sociais estabelecidas em ambientes digitais: principalmente os hipergêneros e o multiletramento. Por essa razão, estabelecemos o seguinte objetivo: desenvolver, aplicar e avaliar práticas leitoras e de produção de textos em sala de aula, com base em hipergêneros, no estudo da língua materna, visando promover o multiletramento de alunos do EM, considerando o preparo desses jovens para lidar com os contextos emergentes nos quais os diversos textos são socializados na contemporaneidade.

O levantamento bibliográfico serviu de base para a compreensão da realidade do estudo e para a aplicação prática dos conceitos-chave em sala de aula, conforme já mencionados; a investigação sobre os traços característicos dos sujeitos da pesquisa foi de suma importância, pois, sem essa análise, haveria muitas chances de criar uma proposta irrelevante para o contexto educacional onde a pesquisa foi realizada. Além disso, ao longo do trabalho, a compreensão de letramento deveria ser considerada como letramentos múltiplos ou multiletramentos, pois, ao lidar com diversos gêneros discursivos, são necessários diversos letramentos. Além disso, o conceito de multiletramento visa considerar a multiplicidade semiótica presente no texto, intentando habilitar os cidadãos a negociar significados por intermédio de linguagens permeadas por variações, propondo um novo senso de vida cívica baseada por vezes na diferença e por outras na similaridade. Já criação dessas atividades consistiu na principal tarefa deste trabalho, pois foi nossa intenção, desde o princípio, materializar de maneira prática a teoria mobilizada, na forma de sequências didáticas relevantes tendo em vista os sujeitos-alvo da pesquisa. $\mathrm{O}$ hipergênero selecionado (corpus principal) mostrou-se altamente versátil, pois, a partir dele, tornou-se possível promover o contato dos alunos com vários gêneros discursivos (a história fantástica, a narrativa mitológica, o relato histórico, o debate, o e-mail de opinião, a cantiga, o poema, a adivinhação, a resenha, entre outros) e alcançar os pressupostos para o multiletramento. Também contamos com a otimização da pesquisa-ação no processo metodológico, ao estipular etapas muito distintas, todas elas com início e fim delimitados, a fim de alcançar os objetivos propostos.

Os estudantes que participaram da pesquisa enquadram-se nas características levantadas na fundamentação teórica, demonstrando uma constante 
inquietação em sala de aula e, ao mesmo tempo, um apreço exagerado por seus celulares e smartphones. Já a escola em que a pesquisa foi realizada transpareceu reproduzir um contexto escolar reconhecido como "tradicional", no qual permanecem as mesmas práticas pedagógicas há muito conhecidas e já cristalizadas. Entretanto, ao não realizar práticas de ensino integrais que abordem a questão dos gêneros no ambiente digital, a escola deixa de proporcionar aos alunos um contato importante e um estímulo ao pensamento crítico sobre situações que serão invariavelmente experienciadas em suas vidas cotidianas.

Com esta pesquisa tivemos a pretensão de contribuir para o desenvolvimento de práticas educacionais que utilizam as TICs no estudo da língua materna, bem como auxiliar na melhor compreensão da realidade comunicacional estabelecida no ambiente virtual, considerando as implicações que os hipergêneros e suas características discursivas trazem para o ensino de língua.

Algumas das claras limitações encontradas durante a realização deste estudo foram: o fator tempo e o fato de os pesquisadores não serem os professores efetivos da turma de EM com a qual se trabalhou. Afirmamos isso porque cremos que, ao conhecer melhor os alunos e poder realizar uma pesquisa-ação com um maior número de ciclos, poderíamos, talvez, obter resultados mais substanciais e ter mais chances de interferir na realidade na qual levantamos o problema de pes- quisa. Dessa forma, sugerimos a realização de outros trabalhos com a mesma temática que possam, por exemplo, desenvolver e ampliar a compreensão de leitura e de interpretação em hipergêneros. Além disso, buscamos motivar outros pesquisadores a se dedicarem sobre a temática em seus processos de qualificação continuada, refletindo sobre assuntos diversos dentro do universo das letras, aprofundando seu conhecimento sobre linguística e/ou literatura, para que de forma mais efetiva possam contribuir para um panorama mais qualitativo no cenário educacional em nosso país.

\section{Hypergenres and multiliteracy in mother tongue teaching: experience using ICTs in the classroom}

\begin{abstract}
This research has as its theme the use of information and communication technologies (ICTs) in the high school context. Its objective is to apply classroom activities to study the mother tongue, based on hypergenres intended to promote student's multiliteracies. Such study is justified because it is noticeable the fast pace at which ICTs are implemented, which has generated new forms and interaction tools and, consequently, new genres and/or hybridization of existing ones. The theoretical base is mainly founded on Maingueneau (2005, 2010) about hypergenres and on Rojo (2009, 2012, 2013) about multiliteracies and reading on hypermidia based on Santaella $(2004,2007$, 2013). With respect to methodology,
\end{abstract}


it is an exploratory and bibliographic research, developed through action research carried out in a public high school. As a result, it is highlighted that the adoption of hypergenes and the use of ICTs in the study of the mother tongue may support the acquisition of multiliteracies in the high school context.

Keywords: Hypergenres. Multiliteracy. ICTs.

\section{Referências}

ALMEIDA, M. E. B. de. Letramento digital e hipertexto: contribuições à educação. In: PELLANDA, N. M.; SCHLÜNZEN, E. T.; SCHLÜNZEN JÚNIOR, K. (Org.). Inclusão digital: tecendo redes afetivas/cognitivas. Rio de Janeiro: DP\&A, 2005. p. 171-192.

ARCOVERDE, M. D. de L.; ARCOVERDE, R. D. de L. Leitura, interpretação e produção textual: Gêneros textuais ou discursivos. Campina Grande: UEPB; Natal: UFRN, 2007.

BAKHTIN, M. Os gêneros do discurso. In: . Estética da criação verbal. São Paulo: Martins Fontes, 1997. p. 277-326. cap. 6.

BAKHTIN, M. (VOLOCHÍNOV, V. N.). Marxismo e filosofia da linguagem: problemas fundamentais do método sociológico da linguagem. 14. ed. São Paulo: Hucitec, 2010.

BRASIL. Parâmetros Curriculares Nacionais: Língua Portuguesa. Brasília, DF: MEC/ SEF, 1997.

. Parâmetros Curriculares Nacionais: terceiro e quarto ciclos do ensino fundamental: Língua Portuguesa. Brasília, DF: MEC/ SEF, 1998.

Parâmetros Curriculares Nacionais: ensino médio: Linguagens, códigos e suas tecnologias. Brasília, DF: MEC/SEMTEC, 2000 .
. PCN + Ensino Médio: orientações educacionais complementares aos Parâmetros Curriculares Nacionais. Brasília, DF: MEC/SEMTEC, 2002.

CORACINI, M. R. F. Concepções de leitura na (pós-)modernidade. In: LIMA, R. C. de C. P. (Org.). Leituras: múltiplos olhares. Campinas: Mercado das Letras; São João da Boa Vista: Unifeob, 2005. p. 15-44.

DIAS, A. V. M. Hipercontos multissemióticos. In: ROJO, R. H. R.; MOURA, E. (Org.). Multiletramentos na escola. São Paulo: Parábola, 2012. p. 95-111.

INEP. Índice de Desenvolvimento da Educação Básica (Ideb). 2011. Disponível em: <http://ideb.inep.gov.br/resultado/>. Acesso em: 20 mar. 2014.

INSTITUTO PRÓ-LIVRO. $3^{\underline{a}}$ edição da pesquisa Retratos da leitura no Brasil. Ibope Inteligência, 2011. Disponível em: <http:// www.prolivro.org.br/ipl/publier4.0/dados/ anexos/>. Acesso em: 21 mar. 2014.

KALANTZIS, M.; COPE, B. Changing the role of schools. In: COPE, B.; KALANTZIS, M. (Org.). Multiliteracies: literacy learning and the design of social futures. New York: Routledge, 2000. p. 117-144.

LEMKE, J. L. Letramento metamidiático: transformando significados e mídias. Revista Trabalhos em Linguística Aplicada, Campinas: IEL/Unicamp, v. 49, n. 2, p. 455-479, 2010. Disponível em: <http://www.scielo.br/pdf/tla/ v49n2/09.pdf>. Acesso em: 17 abr. 2014.

LÉVY, P. O que é o virtual? São Paulo: Editora $34,1996$.

MAINGUENEAU, D. Genre, hypergenre, dialogue. Calidoscópio, São Leopoldo: Unisinos, v. 3, n. 2, p. 131-137, maio/ago. 2005.

Cenas da enunciação. São Paulo: Parábola, 2008a.

. Ethos, cenografia e incorporação. In: AMOSSY, Ruth. Imagens de si no discurso: a construção do ethos. São Paulo: Contexto, 2008b. p. 69-92. 
Hipergênero - Hipergênero, gênero e internet. In: Doze conceitos em análise do discurso. São Paulo: Parábola, 2010. p. 129-138. Sírio Possenti e Maria Cecília Perez de Souza-e-Silva (Org.).

Discurso literário. 2. ed. São Paulo: Contexto, 2012.

Análise de textos de comunicação. 6. ed. ampl. São Paulo: Cortez, 2013.

MARCUSCHI, L. A. Gêneros textuais: definição e funcionalidade. In: DIONÍSIO, Â. P. Gêneros textuais \& ensino. Rio de Janeiro: Lucerna, 2002. p.19-36.

Produção textual, análise de gêneros e compreensão. São Paulo: Parábola, 2008.

NEW LONDON GROUP. A pedagogy of multiliteracies: designing social futures. In: COPE, B.; KALANTZIS, M. (Org.). Multiliteracies: literacy learning and the design of social futures. New York: Routledge, 2000. p. 9-36.

O HOBBIT - Viagem pela Terra Média. Website da Warner Bros. Ent. Disponível em: $<$ http://middle-earth.thehobbit.com $>$. Acesso em: 31 out. 2014.

POSSENTI, S. Um dispositivo teórico e metodológico. In: POSSENTI, S.; BARONAS, R. L. Contribuições de Dominique Maingueneau para a análise do discurso no Brasil. São Carlos: Pedro \& João Editores, 2008. p. 201-213.

PRODANOV, C. C.; FREITAS, E. C. de. Metodologia do trabalho científico: métodos e técnicas da pesquisa e do trabalho acadêmico. 2. ed. Novo Hamburgo: Feevale, 2013. Disponível em: <http://www.feevale.br/ Comum/midias/8807f05a-14d0-4d5b-b1ad1538f3aef538/E-book Metodologia do Trabalho Cientifico.pdf>. Acesso em: 30 out. 2013.

ROJO, R. H. R. Letramento(s) - Práticas de letramento em diferentes contextos. In: . Letramentos múltiplos, escola e inclusão social. São Paulo: Parábola, 2009. p. 95-121.
. Pedagogia dos multiletramentos. In: ROJO, R. H. R.; MOURA, E. (Org.). Multiletramentos na escola. São Paulo: Parábola, 2012. p. 11-31.

Gêneros discursivos do círculo de Bakhtin e multiletramentos. In: ROJO, R. H. R. (Org.).Escol@ conectada: os multiletramentos e as TICs. São Paulo: Parábola, 2013. p. 13-36.

SANTAELLA, L. Navegar no ciberespaço-O perfil cognitivo do leitor imersivo. São Paulo: Paulus, 2004.

Linguagens líquidas na era da mobilidade. São Paulo: Paulus, 2007.

Desafios da ubiquidade. Revista Ensino Superior Unicamp, Campinas: Unicamp, v. 9, p. 19-28, abr./jun. 2013.

SOARES, M. Letramento: um tema em três gêneros. 2. ed. Belo Horizonte: Autêntica, 2001.

Novas práticas de leitura e escrita: letramento na cibercultura. Educação \& Sociedade, Campinas, v. 23, n. 81, p. 143160, dez. 2002.

UNESCO. Educação e aprendizagem para todos: olhares dos cinco continentes. Brasília, DF: Unesco, Ministério da Educação, 2009. Disponível em: <http://www.unesco.org/fileadmin/>. Acesso em: 20 mar. 2014.

ZILBERMAN, R. A escola e a leitura da literatura. In: ZILBERMAN, R.; RÖSING, T. (Org.). Escola e leitura. Velha crise, novas alternativas. São Paulo: Global, ALB, 2009. p. 17-39. 